\title{
Countermeasure Study of Green Transportation Development in the Context of Supply-side Structural Reform
}

\author{
Anqi Lv ${ }^{1 *}$, Dong Xin², Zhoukai Wang ${ }^{3}$ and Liyong $\mathrm{Li}^{4}$ \\ ${ }^{1}$ Research Institute of Highway Ministry of Transport / Zhonglu Gongke (Beijing) Investment \& Consulting Co., Ltd., Beijing, 100088, \\ China \\ ${ }^{2}$ Jiaoke Transport Consultants Ltd., Beijing, 100191, China \\ ${ }^{3}$ Zhejiang Provincial Highway and Transportation Management Center, Hangzhou, Zhejiang, 310006, China \\ ${ }^{4}$ Hangzhou Transportation Development Service Center, Hangzhou, Zhejiang, 310014, China
}

\begin{abstract}
Green transportation is the most urgent transportation transformation choice in the area of rapid urban expansion and sustainable economic development. It is an important embodiment of the concept of urban sustainable development in transportation. This paper analyzes the status quo and problems of green transportation development of the case study of Zhejiang Province from several aspects such as equipment transportation, trip environment, transport efficiency and management ability,as well as the situation facing; propose the key tasks in improving comprehensive transportation system, constructing ecological infrastructure, popularizing energy-saving and environmental protection transportation equipment, developing intensive and efficient transportation organization, promoting science and technology leading and intelligent transportation; and finally, expound the guarantee measures of green transportation construction.
\end{abstract}

\section{Introduction}

In the reports of the 19th National Congress of the Communist Party of China, General Secretary Xi Jinping made it clear, ecological civilization is a millennium plan for the sustainable development of the Chinese nation. He made a comprehensive plan for accelerating the institutional reform of ecological civilization and building a beautiful China in the new era. Green transportation is the important characteristic and intrinsic requirement of a traffic powerful country. The transportation industry has fully implemented the new concepts, new thoughts and new strategies of the CPC central committee with comrade Xi Jinping at the core on ecological progress, vigorously promoted the scientific development of transport, and made positive achievements in green transportation. But on the whole, there are still some problems, such as relatively extensive mode of transportation development, unreasonable transportation structure and imperfect green transportation management system, which is difficult to effectively meet the people's growing needs for a beautiful ecological environment in the new era.

As one of China's most economically dynamic provinces, the contradiction among economic development, resource constraint and environmental burden of Zhejiang Province has also taken the lead. Its green transportation development is particularly important in the context of national economic development entering a new normal. Under the overall requirements of the transportation industry to promote the supply-side structural reform, Zhejiang's transportation needs to accelerate the transformation of the development mode, realize the long-term green development of transportation, and comprehensively support the ecological civilization construction and green economic development.

\section{Analysis on the development status and problems of green transportation in Zhejiang Province}

\subsection{Development status}

Zhejiang provincial transportation sector spares no effort to promote the construction of large ports, large network, large logistics, large water transport and large aviation, at the same time, constantly improves the concept of development, promoting the development of green, circular and low-carbon transport as an important task to implement the transport infrastructure construction, transport production and industry management in all links. It has effectively played the role of government guidance, market orientation and enterprise main body with remarkable results. Highlights are shown in the construction of modern comprehensive transportation system, promotion of scientific and technological innovation, priority promotion of low-carbon transportation by public transportation, development of

$\overline{{ }^{*} \text { Corresponding author's e-mail: } 254836782 @ q q . c o m}$ 
intelligent transportation, construction of standard specification system, and construction of multi-sector coordination and linkage guarantee mechanism. It has made positive contributions to the realization of provincial energy conservation and emission reduction targets and the construction of "Two Optimal Constructions of Zhejiang" (to optimize environment and people's life).

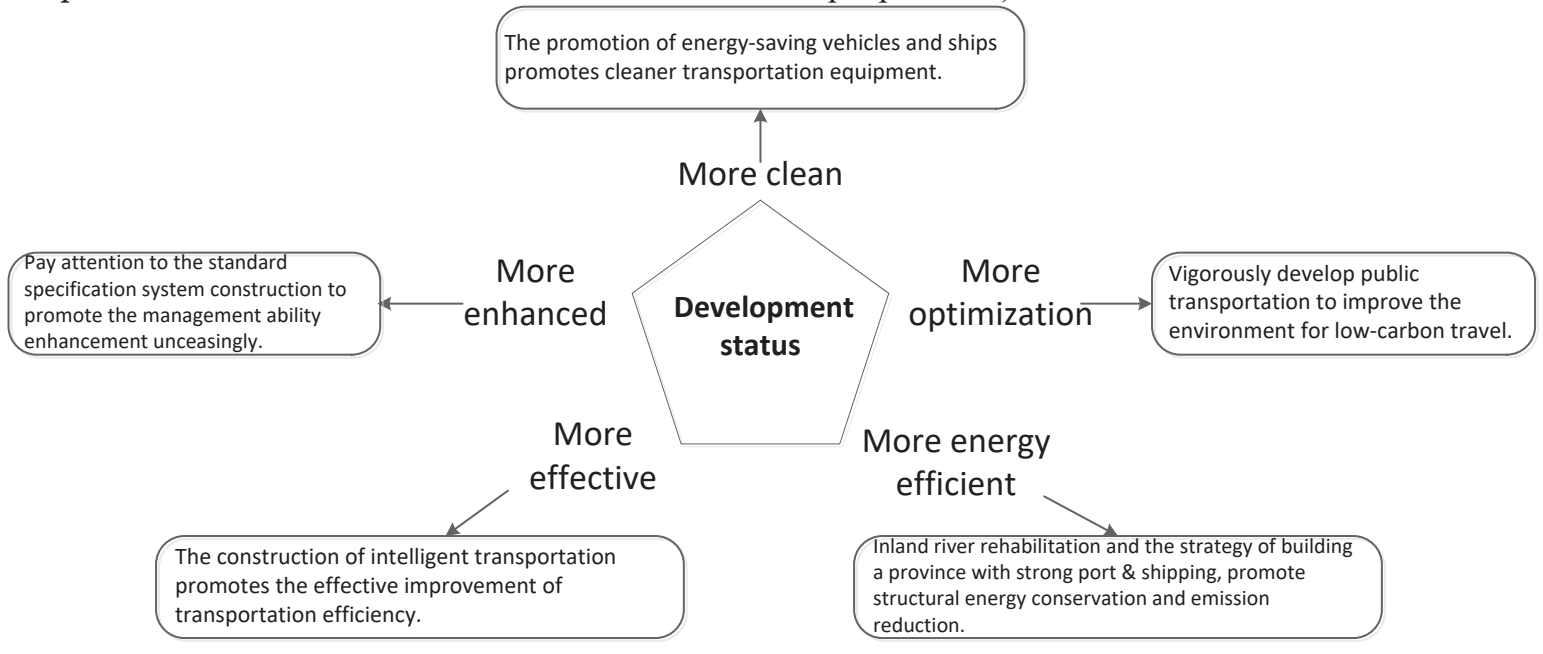

Figure 1. Analysis on the development status of green transportation.

\subsubsection{The promotion of energy-saving vehicles and ships promotes cleaner transportation equipment}

Zhejiang has made Opinions On Speeding Up Implementation of Elimination of Old Commercial Vehicles, vigorously promoting the early phasing and upgrading of diesel trucks operating at or below National III emission standards, speeding up the elimination of old gas vehicles that use lean combustion technology and "oil to gas", so as to further strengthen pollution source control of transport vehicles, improve environmental access standards, strictly enforce limits on fuel consumption for operating vehicles and phased emission standards for motor vehicles, and enhance vehicle inspection to restrict the access of energy-intensive and high-emission vehicles to the road transport market at the source. Additionally, the energy consumption structure of commercial vehicles will be optimized to promote the rapid development of new and clean energy vehicles such as pure electric vehicles, gas-electric hybrid vehicles and natural gas vehicles in operation of urban public transportation, taxi and commercial other vehicles.

\subsubsection{Vigorously develop public transportation to improve the environment for low-carbon travel}

Zhejiang Province has made great efforts to develop public transportation, improve transportation service level, optimize low-carbon travel environment, and guide the public to choose low-carbon travel mode. Taking the city's traffic control as an opportunity, we carried out three activities: improving urban public transportation, speeding up the 100-line shuttle buses and creating a public transportation demonstration city. We have implemented ten major measures to improve urban public transportation, focusing on 146-line shuttle bus routes in the province, and promoted the acceleration of bus speeds through the implementation of "four shortening". We will promote the establishment of national "Transit-oriented Cities" and provincial "Transit Priority Demonstration City". The province has issued a series of policies and measures, including Notice on Launching the creation of Transit-oriented Cities and Transit Priority Demonstration City, Implementation Opinions of Zhejiang Provincial People's Government on Urban Priority Development of Public Transportation, Guidelines for Compilation of Urban Public Transportation Development Planning in Zhejiang Province, Notice on Ensuring the Priority of Urban Public Transportation, etc. Meanwhile, in recent years, Zhejiang Province has made great efforts to develop public bicycles, effectively solving the "last kilometer" problem for people traveling. It has played a very important role in promoting green and low-carbon transportation and has been highly recognized by the people.

\subsubsection{Inland river rehabilitation and the strategy of building a province with strong port \& shipping, promote structural energy conservation and emission reduction}

Zhejiang Province vigorously promotes the development of water transport, the development of sea-river joint transportation and public water transportation, and the construction of large ports comprehensively, actively developing large and specialized ports, and giving full play to the comparative advantages of inland waterways and sea-river joint transportation advantages, to guide the low-carbon transformation of transport structure. Zhejiang Province improves the transport infrastructure, optimizes the layout of road passenger and freight yard, and comprehensively promote the construction of a large road network, speeding up the formation of a network structure of high-speed trunk lines, high-speed sub-trunk lines and encrypted branch lines, implementing nine master plans for national highway transportation hub 
cities, so as to promote "zero distance transfer" and "seamless connection" of passenger and cargo transportation.

\subsubsection{The construction of intelligent transportation promotes the effective improvement of transportation efficiency}

Zhejiang Province speeds up research and development, and application of modern information technology in the field of transportation, and integrates it into the whole industry, field and process of transportation. The province actively promotes the construction of highway and waterway safety and emergency response projects, and enhances the emergency response capacity of transportation by means of informatization. Realize the "full coverage" of expressway electronic toll collection system and the highway electronic toll collection overload disposal system within the whole province; popularize production service management systems such as tunnel ventilation and lighting control, and implement pilot construction of bridge remote health monitoring system. Carry out comprehensive promotion of integrated bus and crew scheduling and urban taxi intelligent scheduling. Actively build and constantly optimize the public travel service system, establish resource-sharing government public information service platform and management information platform, constantly improve the public travel information service system, and provide timely, accurate and efficient information for public travel and cargo transportation.

\subsubsection{Pay attention to the standard specification system construction to promote the management ability enhancement unceasingly}

Zhejiang Province has actively explored the effective mechanism of multi-sector coordination and linkage to promote the development of green transportation, striving to ensure the efficient operation and scale promotion of green circular and low-carbon transportation with a sound system. Zhejiang has formulated a number of comprehensive plans including The 13th Five-year Plan for Comprehensive Transportation Development of Zhejiang Province, which has made remarkable achievements in promoting the coordinated development and organic connection of various transportation modes and guiding the low-carbon transformation of transportation structure. We will establish a sound regulatory framework for energy conservation and emission reduction; take the lead in releasing the country's first local standards for public bicycles - Management Service Specification of Urban Public Bicycle System and Technical Specification for Engineering Design of Urban Public Bicycle System, and compile the national standards for transportation industry - Highway Energy-storage Self-luminous Traffic Signs and Green Maintenance (Spray Booth) Industry Standards. We have actively explored effective mechanisms for multi-sector coordination and linkage to promote the development of green transportation.
Multiple sectors provide strong support and coordination for energy conservation and emission reduction in transportation in aspects of planning, policy, resources, information, etc.

\subsection{Existing problems}

\subsubsection{The level of energy-saving and low-carbon transportation equipment needs to be improved}

Although in recent years, Zhejiang Province has increased the promotion and application of new energy and clean energy vehicles and ships, however, restricted by objective factors such as gas source situation and technological development, at present, road passenger and freight vehicles and waterborne ships, which account for a large proportion of energy consumption in the transportation industry, still mainly use diesel, gasoline and fuel oil. The level of energy-saving and low-carbon transportation equipment needs to be improved urgently

\subsubsection{Policies and systems for energy conservation and emission reduction in transportation still need to be improved}

Zhejiang has made good progress in establishing organizations for transportation energy conservation and emission reduction, compiling special plans for industry energy conservation and emission reduction, establishing a statistical monitoring and assessment system for energy conservation and emission reduction, and conducting publicity, promotion and training. However, the system of energy conservation and emission reduction guarantee system needs to be further refined and improved in the process of implementation. In particular, we need to continue to explore the promotion of market mechanisms for energy conservation and emission reduction.

\subsubsection{The statistical monitoring system of energy consumption needs to be further optimized}

The statistical basis of energy consumption in various fields of transportation is not uniform; the statistical means are relatively single, and the reliability of statistical data needs to be improved. In the future, we need to further optimize the statistical system, design a more comprehensive and reliable monitoring system, and do a good job in the long-term collection, preservation, sharing, utilization and analysis of data, so as to provide data support for the work of energy conservation and emission reduction in transportation.

\section{Situation of green transportation development in Zhejiang Province}

\author{
3.1 The strategy of building a powerful traffic \\ country has pointed out the direction for the \\ development of green transportation.
}


Green transportation is the important characteristic and intrinsic requirement of building a powerful traffic country. Opinions on Promoting the Development of Green Transportation in An all-round and In-depth Way (hereinafter referred to as Opinions) issued by the Ministry of Transport, clarify the overall requirements and development goals of green transportation, and put forward seven major projects to promote the implementation of green transportation development and three major institutional guarantee systems for green transportation development. In terms of guiding ideology, it highlights the requirements of "Xi Jinping Thought on Socialism with Chinese Characteristics for a New Era", "upholding the harmonious coexistence between man and nature", "socialist ecological civilization view" and "the conviction that lucid waters and lush mountains are invaluable assets", promoting green transportation to make the transition from passive adaptation to leading in advance, from pilot projects to all-round promotion, and from government driven to universal rule, and promoting green development and lifestyle, so as to provide solid support and strong guarantee for building a beautiful China, improving people's livelihood, and meeting people's aspiration for a better life.

\section{2 "Two Optimal Constructions of Zhejiang" provides opportunities for the development of green transportation.}

Decisions on Building a Beautiful Zhejiang for A Better Life issued by CPC Zhejiang Provincial Party Committee puts forward that, by 2020, we will strive to build a national demonstration zone for ecological progress and a pilot zone for beautiful China; we have made all-round breakthroughs in optimizing the development pattern, accelerating industrial upgrading, conserving energy and resources, advocating a civilized and thrifty life, and innovating the system of ecological civilization; we shall work hard to achieve transformation, upgrading, and ecological governance taking the "common governance of five rivers " as a breakthrough. We encourage all sectors of society to participate in, supervise, build and share together, and strive to form a strong synergy for the whole society to participate in the construction of a beautiful Zhejiang taking co-construction and sharing as the main channel. "Two Optimal Constructions of Zhejiang" has drawn a general blueprint and pointed out the general direction for the ecological civilization construction of all industries in Zhejiang Province, and has also brought unprecedented historical opportunities for accelerating the green, circular and low-carbon development of transportation.

\subsection{The increasingly prominent contradiction between resources, energy and environment has accelerated the development of green transportation.}

As an energy-intensive and resource-intensive industry, transportation is an important field of energy consumption, especially oil consumption, which relies heavily on land, coastline, building materials and other key resources. However, the basic situation of Zhejiang Province is dense population, poor per capita endowment of resources, shortage of land, high dependence on external energy, especially the shortage of natural gas sources. At present, the energy structure of transportation industry in Zhejiang Province is still dominated by fossil fuels such as coal, oil and natural gas. The "high carbon" feature of the economic and energy structure is very prominent. Therefore, it is particularly urgent for the transportation industry to speed up the implementation of green circular and low-carbon development.

\section{Key Tasks of Zhejiang Green Transportation Development}

\subsection{Improvement of integrated transportation system}

Road transport management department shall drive the coordinated development of all modes of transportation, focus on the construction of integrated transportation hub and its collection \& distribution system supporting facilities, promote the seamless connection for freight transportation and zero-distance transfer for passenger transportation, and speed up the construction of Ningbo south integrated passenger transportation hub and other integrated passenger transportation hubs connected to the railway, accelerate the construction of integrated transportation center for Hangzhou, Ningbo and Wenzhou these three major airports, accelerate the construction of logistics park linking at least two modes of transportation, such as Meishan bonded port logistics park connected to the seaport, Deqing Linhang logistics park connected to the inland river, Ningbo airport logistics park connected to the air freight, Panqiao international logistics base connected to the railway, etc.

By virtue of superior water transportation conditions of Zhejiang Province, shipping department shall give full play to its huge energy-saving advantages, and put forth effort on the implementation of inland shipping revival plan; build a coastal port system with reasonable structure and perfect function, an inland waterway system with trunk and branch lines connected to rivers and seas directly, as well as a collection \& distribution system supporting rail-and-water transportation and river-ocean combined transportation; strengthen the "one main plus two auxiliaries" coastal port development pattern that is based on Ningbo-Zhoushan Port \& Jiaxing Port and supplemented by Wenzhou and Taizhou. Highway management department shall enhance the expansion and rehabilitation of main channel, speed up the construction of highways connected to the surrounding provinces and cities including Yangtze River Delta region and West-Straits Economic Zone, perfect the collection \& distribution channel of ports and airports, and optimize the layout of provincial highway network; accelerate the construction of national \& provincial trunk roads; focus on the construction of highway network, reduce the number of dead end highways, and form a stereo-traffic network with urban- 
rural integration and regional coordination to achieve mutual supporting among the highways, ordinary national \& provincial roads, and rural roads.

Improvement of integrated
transportation system
Speed up the construction of
Ningbo south integrated
passenger transportation hub
and other integrated
passenger transportation
hubs connected to the
railway.
Accelerate the construction of
integrated transportation
center for Hangzhou, Ningbo
and Wenzhou these three
major airports.
Speed up the construction of
highways connected to the
surrounding provinces and
cities including Yangtze River
Delta region and West-Straits
Economic Zone.

Construction of green
ecological infrastructure
Under the highway
construction, encourage the
rebuilding and expansion of
old roads, and control the
construction land occupancy
by adopting measures suiting
local conditions.
Improve the quality and
technical level of waterway
maintenance, and put
emphasis on the maintenance
of Beijing-Hangzhou Canal,
Hang-Yong Canal, Hangshen
Line, Changhushen Line,
Hanghuxi Line and other
waterways, so as to ensure
the integrity and unimpeded
flow of the main waterways.

Popularization of energy-
efficient and eco-friendly
transportation equipment

Development of intensive
and efficient mode for
transportation organization

Promotion of technology-
led and intelligent
transportation

Figure 2. Key tasks of green transportation development.

\subsection{Construction of green ecological infrastructure}

During the construction of transportation infrastructure, highway construction department shall reduce the land occupancy, resource overburden, as well as damage to the ecological environment as much as possible, encourage the rebuilding and expansion of old roads, and control the construction land occupancy by adopting measures suiting local conditions, including the design of "Low Road Embankment" and the method to increase the proportion of bridges and tunnels, optimize the highway project construction scheme, make the best use of barren mountain, wasteland and abandoned land, reduce the occupancy of farmland, woodland and cash crop land; attach importance to the restoration of temporary construction land and borrow \& spoil ground, and encourage the reclamation measures to be taken in the course of project construction, so as to achieve economical utilization of land resources. Through the promotion in grade, technology improvement, equipment update, land area expansion, supporting facility perfection and other methods, highway construction department shall encourage to strengthen the technical transformation of old port area and enhance the utilization efficiency of coastal resources in the old port area.

The competent transportation department shall apply LED lighting technology and wind-solar complementary lighting technology in the highway, waterway, bridge, tunnel and roadside facilities, and push forward the tunnel "green lighting project"; encourage the rational utilization of construction \& industrial waste materials, dredged soil, machine-made sand, and achieve the balance of earth-rock resources; drive the treatment of domestic sewage in the highway service area, and promote the sewage disposal and cyclic utilization in the service area; implement the reclamation, rehabilitation and revirescence schemes of abandoned roads, and improve the greening level of existing roads. Highway management department shall strengthen the preventive maintenance, improve the quality and efficiency of highway maintenance, and improve the durability of highway transportation infrastructure. Shipping department shall improve the quality and technical level of waterway maintenance, and put emphasis on the maintenance of Beijing-Hangzhou Canal, Hang-Yong Canal, Hangshen Line, Changhushen Line, Hanghuxi Line, Hujiasheng Line, Dongzong Line, Zhajiasu Line, Hangpingshen Line and other waterways, so as to ensure the integrity and unimpeded flow of the main waterways.

\subsection{Popularization of energy-efficient and eco- friendly transportation equipment}

The competent transportation department shall push forward the planning and construction of natural gas stations and charging facilities in the province, accelerate the construction of natural gas stations in the highway service area focusing on Hang-Yong Highway and other highways, and promote the popularization and application of natural gas vehicles focusing on container trucks, long-distance passenger vehicles and tourism buses. Shipping department shall actively promote the pilot application of ships powered by clean energy (e.g., LNG), and popularize the use of battery-powered ships in scenic spots, speed up the replacement work of old ships, improve the energy-use structure and reduce carbon emissions of ships through technological upgrading and energy selection. Road transport management department shall guide the use of freight vehicles and recommended types of road trains, and attach importance to the development of large-tonnage 
multi-axle heavy-duty road trains, container trucks and short-distance collecting \& distributing small freight vehicles suitable for highways and trunk roads, give great impetus to the early elimination and update of diesel trucks operating at level III of national emission standard or below, accelerate the elimination of old gas vehicles adopting lean-burn technology or "oil to gas" technology, and make a good job in pollution control of operating diesel trucks.

Road transport management department shall encourage the popularization and application of automobile conservation technologies and products such as radial tire, guide plate and fan clutch, so as to reduce the energy consumption of ancillary equipment, push forward the recycling and reusing of waste resources in the road transportation and maintenance industry, and establish the basic database to perform real-time monitoring and statistical analysis of waste resources in the automobile maintenance industry of the whole province, promote the clean production of coach cars, and encourage the application of new energy and clean energy vehicles in coach cars, strengthen the detection and maintenance of in-use vehicles, improve the technical conditions of operating vehicles, and control the increase of energy consumption. Shipping department shall develop the large-scale and standardized ships applicable to the waterway technical standards, and encourage the use of container ships, roll-on-roll-off ships, product carriers, liquefied gas carriers and other specialized transport ships, increase the government support for standardization and upsizing of large ships, and improve the development of container ships, product ships, direct ships to rivers and seas and other special ships, guide the development of light-weighted, efficient, electricallydriven and variable-frequency controlled port handling equipment, and enhance the overall technical level of port equipment.

\subsection{Development of intensive and efficient mode for transportation organization}

Road transport management department shall make sustained efforts to enhance the construction of national transportation logistics public information platform, expand and deepen the public information services and other functions of the platform, effectively promote the information exchange and resource sharing of each link in the logistics industry chain, push forward the coordination and integration with the "three-in-one" port and shipping logistics service system, and reduce the logistics costs of the whole society, based on the massive economy and industrial clusters throughout the province, innovate and popularize a development mode of "highway port", promote the integration of all kinds of special line logistics resources, and build a high-speed special line logistics network covering Yangtze River Delta region and whole country, so as to realize the intensified, branded and optimized operation of special line logistics. Relying on the inland waterway system in Hangzhou-Jiaxing-Huzhou area, shipping department shall strive to develop the inland waterway container transportation, and actively carry out the sea-river joint transportation with Shanghai Port and Ningbo-Zhoushan Port. Relying on the improvement of Oujiang waterway in southern part of Zhejiang Province, develop the inland waterway container transportation, and actively carry out the sea-river joint transportation with Wenzhou Port and Taizhou Port, guide the shipping enterprises to develop in the direction of large scale and intensification, and encourage them to adopt the collectivized management mode through reorganization, joint venture, shareholding system, etc., explore the establishment of port alliance, and promote the integration of port resources.

Road transport management department shall effectively integrate the resources of intercity passenger lines, and build a "Zhejiang Transhipping Alliance" brand, promote the public transport transformation of short-distance lines with adjoining provinces, coordinate to build the special intercity and section bus shelters and flag stops. Innovate the organization mode of rural passenger transportation, take into full consideration of travel demands by people along the lines, unify the service standards and enhance the service quality through integration of rural line resources. Road transport management department shall implement the public transportation priority strategy in an all-round way, increase the investment in public transportation, guarantee the right to use the roads for urban public transportation, set up, extend and transform the regular bus lines timely depending on the change of city pattern, increase the fleets of buses and expand the coverage area of bus stations, determine the size of taxi transport capacity, and achieve a reasonable and orderly growth of taxi transport capacity, improve the travel environment for various means of transportation including walking and cycling, realize a harmonious development and "zero-distance" transfer between urban public transportation and taxi, car, bicycle rental.

\subsection{Promotion of technology-led and intelligent transportation}

The competent transportation department shall insist on taking the technological innovation as the strategic basis of ecological transportation construction as well as the key link in transforming the mode of transportation growth, optimize the allocation of technological resources, make breakthroughs on key technologies for ecological construction, give major support and great impetus to R\&D and application of new technologies and products for energy conservation, emission reduction, environmental protection, and integrated utilization of resources, guide the enterprises to increase investment in technological transformation, and actively promote the new technologies for energy conservation and emission reduction, speed up the formulation, revision, publicizing and implementation of the standard specifications related to green transportation, enhance the leading role of standard specifications in the construction of green transportation system, and form a long-term mechanism of green transportation development. 
In the field of highway construction, the emphasis is to promote the popularization and application of selfluminous traffic signs and foam asphalt cold regeneration standard specifications throughout the province. In the field of port and shipping, the main task is to promote the popularization and application of technical specifications for overall jacking of inland bridges. In the field of road transportation, the focus is to promote the popularization and application of the public bicycle system technology $\&$ management specifications and the green maintenance standard specifications throughout the province. The competent transportation department shall apply information technology to enhance the intelligence level of transportation organization and industry supervision, and make sustained efforts to promote the pilot work of smart port and shipping, smart logistics, and smart urban transportation, as well as to promote the construction of emergency traffic command centers and urban traffic congestion index release systems.

\section{Safeguard Measures of Zhejiang Green Transportation Development}

In order to ensure the green transportation development in Zhejiang Province, it is necessary to establish a perfect organizational structure and leadership mechanism, strengthen the coordination among departments, build a low-carbon transportation management system in collaboration with multiple departments, strictly implement the operation management plan, perfect the relevant system standards, raise funds from many aspects, strengthen the supervision in all areas, perfect the supporting policies, enhance the public awareness, improve the endogenous power and external support for green circular low-carbon transportation development, and finally establish a market-oriented green transportation system that takes the enterprise as the main body, takes the system as the guarantee and takes the law as the constraint, so as to lay a foundation for strategic goals of accelerating the reform of new-era ecological civilization system, building a beautiful China as well as building a powerful transportation country.

\section{References}

1. Qian Hu (2017) A Study on Xi Jinping's Thought of Ecological Civilization [D]. Zhejiang Sci-Tech University, Hangzhou.

2. Xinghua $\mathrm{Hu}$, Weihong Huang, Yun Zhong, et al. (2015) Exploration and Practice of Green Transportation Theory [M]. China Communications Press, Beijing.

3. Zuojun Li (2012) Report on Development of Green Transformation in China [M]. CPC Central Party School Press, Beijing.

4. Xijun Tang, Bo Gao and Yongjun Ge (2018) Study on Strategic Framework of Zhejiang Green Transportation Development [J]. China Transportation Review (07):15-18.

5. Yufen Zhang (2003) Transportation and Environmental Protection [M]. China Communications Press, Beijing.

6. Honglei Xu (2014) Theoretical Framework and Policy Construction of Green Transportation [J]. Journal of Transport Management Institute Ministry of Transport (06): 12-17,27.

7. Chuantang Yang, (2013) Development of Green Transportation and Co-construction of Beautiful China [J]. China Water Transport (second half month). (12):3.

8. Zhenhua Feng, Jie Guo and Haiying Zhang, (2018) Improvement of Green Transportation Quality Interpretation of Opinions on Promoting All-round Green Transportation Development $[\mathrm{J}]$. China Highway. (3):54-56.

9. Mingyuan Yu, (2014-09-12) Standard Leads Green Transportation to Go further [N]. China Communications News. (005).

10. Fengming $\mathrm{Su}$, (2010) Concept and Realization Approach of Low-carbon Transportation [J]. Transportation Development. (5) 